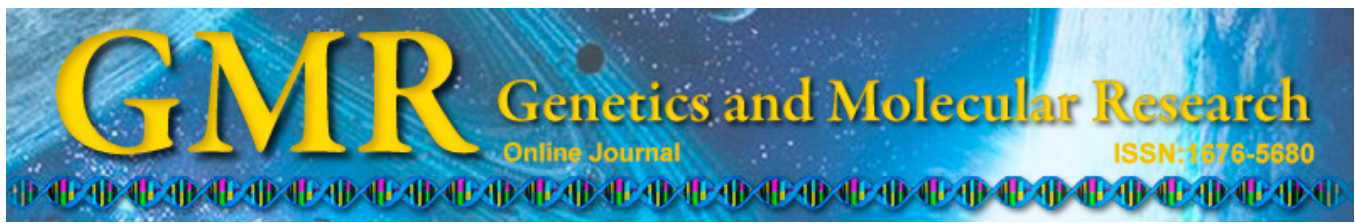

\title{
Genetic polymorphism in sex hormone metabolism and prostate cancer risk
}

\author{
E. Ersekerci ${ }^{1}$, M. Sofikerim ${ }^{2}$, S. Taheri ${ }^{3}$, A. Demirtas ${ }^{1}$ and F. Halis ${ }^{4}$ \\ ${ }^{1}$ Department of Urology, Erciyes University Faculty of Medicine, Kayseri, \\ Turkey \\ ${ }^{2}$ Department of Urology, Acıbadem University Faculty of Medicine, İstanbul, \\ Turkey \\ ${ }^{3}$ Department of Medical Genetics, Erciyes University Faculty of Medicine, \\ Kayseri, Turkey \\ ${ }^{4}$ Department of Urology, Sakarya University Faculty of Medicine, Sakarya, \\ Turkey
}

Corresponding author: M. Sofikerim

E-mail: mustafasofikerim@yahoo.com

Genet. Mol. Res. 14 (3): 7326-7334 (2015)

Received July 7, 2014

Accepted January 29, 2015

Published July 3, 2015

DOI http://dx.doi.org/10.4238/2015.July.3.8

\begin{abstract}
We compared single-nucleotide polymorphisms for point mutations in cytochrome P450 genes, including cytochrome P450c17 $\alpha$ (CYP17), cytochrome P450 aromatase (CYP19), steroid-5- $\alpha$-reductase $(S R D 5 A 2)$, and prostate-specific antigen (PSA) involved in androgen and estrogen production. Between January 2008 and January 2010, 90 patients were enrolled in the study. Of these patients, 28 were diagnosed with benign prostatic hyperplasia and 32 with prostate cancer, while 30 subjects were included as a control group. CYP19 $1531 \mathrm{C}>\mathrm{T}$, SRD5A2 gene V89L, CYP17 gene -34 T/C, PSA-158 (G/A) regions were evaluated for the association between polymorphisms and benign prostatic hyperplasia and prostate cancer in study population. Age, body mass index, peak urinary flow rate (Q max), voided urine volume, post-void residual urine volume, total PSA, free PSA, free/total PSA ratio, prostate weights measured by transrectal ultrasonography, erectile dysfunc-
\end{abstract}


tion score, and international prostate symptom score were compared between groups. No statistically significant difference in CYP19 1531 $\mathrm{C}>\mathrm{T}, S R D 5 A 2 \mathrm{~V} 89 \mathrm{~L}$, and CYP17 -34T/C was observed in both groups when compared to the control group. The homozygote variant of PSA158 (G/A) was significantly lower for prostate cancer. Age, total PSA, free PSA, free/total PSA ratio, prostate weight, and Q max were evaluated using multi-variant analysis. Only Q max was significant for the homozygote variant. The probability of being homozygous was 5.8fold higher in subjects with $\mathrm{Q} \max >14 \mathrm{~mL} / \mathrm{s}$. In the Turkish population, the homozygote variant of $P S A-158(\mathrm{G} / \mathrm{A})$ was significantly lower for prostate cancer.

Key words: Benign prostate hyperplasia; Genetic polymorphism; Prostate cancer

\section{INTRODUCTION}

Benign prostatic hyperplasia $(\mathrm{BPH})$ is an important cause of lower urinary tract symptoms (LUTS) in aging men. Histologically, BPH is characterized by an increased number of epithelial and stromal cells in periurethral areas (Cunha et al., 1983) and is manifested as LUTS, affecting quality of life (Donovan et al., 1997). BPH can cause bothersome LUTS in $30 \%$ of patients older than 65 years (Chapple, 1999). Cancer development depends on abnormal activation of signaling pathways controlling cell proliferation and continuity that play a key role in normal embryological development (Lustig and Behrens, 2003). Epidemiological studies have indicated that the incidence of prostate cancer shows ethnic and regional variations, but the underlying reasons of genetic and environmental factors accounting for the development and progression of prostate cancer are not well-understood (Silig et al., 2006). Currently, prostate cancer is the second leading cause of death following lung cancer in men. According to autopsy studies, the risk of developing prostate cancer is $30-50 \%$ in men approximately 50 years of age, while the risk increases to $80 \%$ at 80 years of age (Whingo et al., 1995). The incidence of prostate cancer is approximately $15 \%$ in developed countries, whereas it is only $4 \%$ in developing countries (Parkin et al., 2001). However, the incidence and mortality of prostate cancer varies because of genetic and environmental factors (Parkin et al., 2005). Prostate growth and function depends on the action of androgens. One of the possible mechanisms in the development of BPH is polymorphisms in the genes encoding enzymes involved in androgen and estrogen metabolism. This process can affect the development and progression of prostate cancer. In this study, we examined the relationships among genetic polymorphisms in the genes encoding cytochrome P450c17 $\alpha$ (CYP17), cytochrome P450 aromatase (CYP19), steroid-5- $\alpha$-reductase (SRD5A2), and prostate-specific antigen (PSA) and susceptibility to prostate cancer and their associations with other clinical parameters.

\section{MATERIAL AND METHODS}

\section{Study population}

This prospective study was conducted at the Departments of Urology and Medical 
Genetics between January 2008 and January 2010. Single-nucleotide polymorphism for point mutations in genes encoding cytochrome P450 enzymes (CYP17, CYP19, SRD5A2, and PSA) and involved in the production and activation of androgen and estrogen were analyzed for their association with symptoms.

Sixty patients who presented to the urology clinic with voiding difficulty were included in the study. All patients enrolled in this study with a PSA value of $>2.5 \mathrm{ng} / \mathrm{mL}$ underwent routine prostate needle biopsy. BPH diagnosis was made by histological evaluation of material obtained via either prostate needle biopsy or transurethral resection of prostate. The prostate cancer group consisted of patients who presented to the urology clinic with any complaint and were diagnosed as prostate adenocarcinoma by either prostate needle biopsy performed because of high PSA values or transurethral resection of prostate performed because of voiding difficulty. Patients older than 50 years without LUTS and cancer diagnosis and who had PSA values lower than $2.5 \mathrm{ng} / \mathrm{mL}$ were randomly assigned to the control group. Of the 90 patients, 28 patients were diagnosed with BPH, whereas 32 were diagnosed with prostate cancer. Thirty patients were employed as controls.

Several parameters were evaluated in patients included in the study. Before the procedure, the following parameters were recorded: age, body mass index (BMI), peak urinary flow rate $(\mathrm{Q} \max )$ value, amount of urine voided, post-voidal amount of residual urine, total PSA, free PSA, free/total PSA ratio, and prostate weight as measured by TRUS, erectile dysfunction score, and international prostate symptom score (IPSS).

\section{Genotyping}

This study was approved by local Ethics Committee. After obtaining informed consent from all subjects, $3 \mathrm{~mL}$ blood was drawn into 2 ethylenediaminetetraacetic acid tubes. Using a Magna Pure LC device (Roche, Basel, Switzerland), DNA and RNA were isolated for polymorphism and gene studies, respectively.

\section{CYP19 1531 C $>$ T polymorphism}

For the CYP19 $1531 \mathrm{C}>\mathrm{T}$ polymorphism, DNA samples were first isolated from patients using the Magna Pure LC device. From these DNA samples, polymerase chain reaction (PCR) was performed using appropriate primers for the CYP19 $1531 \mathrm{C}>\mathrm{T}$ polymorphism. Next, PCR products were run on a $4 \%$ agarose gel (Sigma, St. Louis, MO, USA), which showed a product of 108 base pairs (bp). The bands were extracted and cut with the Bsp 12861 restriction enzyme. After adding distilled water to a total volume of $25 \mu \mathrm{L}$, the sample was incubated overnight at $37^{\circ} \mathrm{C}$. The digestion products were run on a $4 \%$ agarose gel and the polymorphism content was analyzed (Hur et al., 2007). The following products were obtained: 169 and $21 \mathrm{bp}$ for the normal genotype, 190, 169, and $21 \mathrm{bp}$ for the heterozygote genotype, and $190 \mathrm{bp}$ for the homozygote mutant genotype.

\section{SRD5A2 V89L polymorphism}

For the V89L polymorphism of the SRD5A2 gene, DNA samples were first isolated 
from patients using the Magna Pure LC device. The same procedure as described above was employed, except using primers appropriate for the SRD5A2 V89L polymorphism, a 1\% agarose gel, and the $R s a$ I restriction enzyme. The remaining steps were as described above and polymorphisms were identified according to Kakinuma et al. (2004). The following products were obtained: 35 and $89 \mathrm{bp}$ for the normal genotype, 124, 35, and $89 \mathrm{bp}$ for the heterozygote genotype, and $124 \mathrm{bp}$ for the homozygote mutant genotype.

\section{CYP17 -34 T/C polymorphism}

For the CYP17 -34 T/C polymorphism, PCR was performed using a specific primer pair. The PCR products were run on a 3\% agarose gel and CYP17 -34 T/C polymorphism results were obtained according to band sizes. After PCR, the products run on $3 \%$ agarose gel, showing a product of $421 \mathrm{bp}$. The band was excised and cut using MspA1I restriction enzyme. After adding distilled water to obtain a total volume of $25 \mu \mathrm{L}$, it was incubated overnight at $37^{\circ} \mathrm{C}$. After incubation, products were run on $3 \%$ agarose gel to obtain polymorphism results (Xue et al., 2000). The following products were obtained: 421 bp for normal genotype, 421 , 291, and $130 \mathrm{bp}$ for heterozygote genotype and 291,130 bp for homozygote mutant genotype.

\section{PSA-158 (G/A) polymorphism}

For the $P S A-158(\mathrm{G} / \mathrm{A})$ polymorphism, PCR was performed using appropriate primers for the $P S A$ gene. Distilled water was added to a total volume of $50 \mu \mathrm{L}$. Next, PCR products were run on a $2 \%$ agarose gel, which revealed a product of $300 \mathrm{bp}$. The band was excised and cut by the NheII restriction enzyme. After adding distilled water to a total volume of $25 \mu \mathrm{L}$, the sample was incubated overnight at $37^{\circ} \mathrm{C}$. After incubation, the digestion products were run on a 3\% agarose gel and polymorphism results were determined (Chakraborty et al., 2007). The following products were obtained: $150 \mathrm{bp}$ for the normal genotype, 150 and $300 \mathrm{bp}$ for the heterozygote genotype, and $300 \mathrm{bp}$ for the homozygote mutant genotype.

To control whether amplification and the digestion products were accurate, the PCR products were run on an agarose gel. Before electrophoresis, $6 \mathrm{X}$ loading buffer was added to the PCR and restriction fragment length polymorphism products, accounting for $10 \%$ of the total amount loaded. Size marker was loaded to first and last wells on the gel to determine product sizes. The gel was run at $85 \mathrm{~V}$ for 30 min and images were captured using a UV transilluminator as shown in Figure 1.

\section{Statistical analysis}

SPSS 10.0 for Windows (SPSS, Inc., Chicago, IL, USA) was used for all statistical analyses to calculate the mean and range. Distributions of categorical variables were compared using the Pearson correlation test. Comparison of continuous variables was performed using the Mann-Whitney $U$ test. Logistic regression analysis was used to define the relative risk assessment of prostate cancer based on clinical variables combined with single nucleotide polymorphisms. P values $<0.05$ were considered to be statistically significant. 


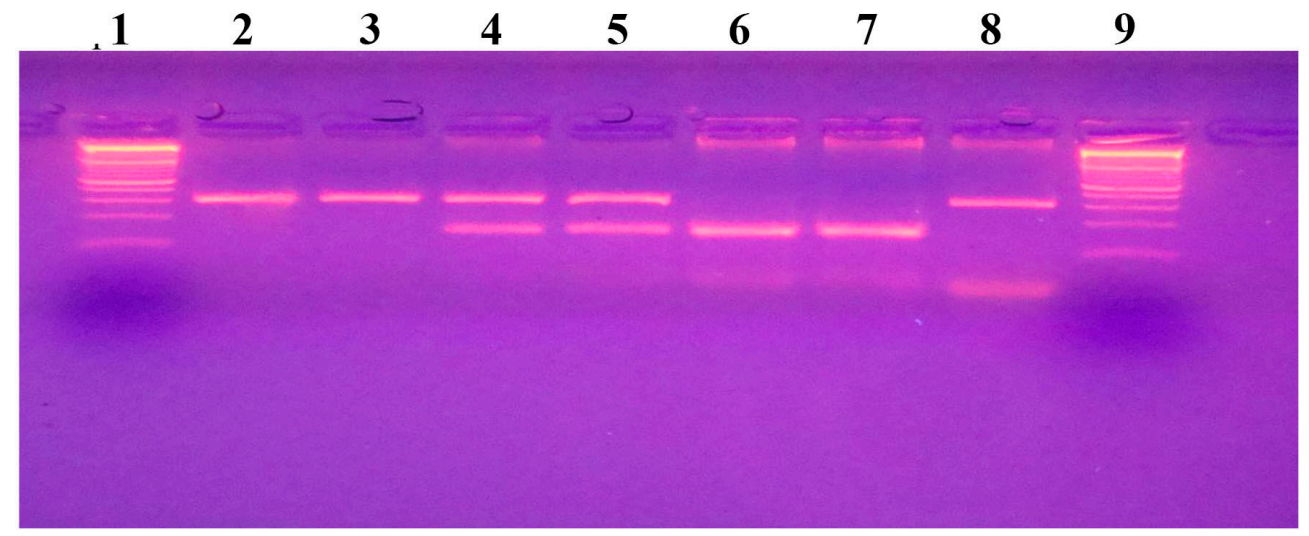

Figure 1. Gel photograph of PCR-restriction fragment length polymorphism amplification of PSA-158 (G/A) polymorphism. Lanes 1 and $9=$ DNA size markers, lanes 2-3 = AA genotype (300 base pairs), lanes 4-5= AG genotype (150 and 300 base pairs), lanes $6-7=\mathrm{GG}$ genotype ( 150 base pairs), lane $8=$ PCR product.

\section{RESULTS}

Mean age was calculated to be 65.5 (52-78) years in patients with BPH, $68.2(51-83)$ years in patients with prostate cancer, and 62.8 (52-78) years in the control group. A significant difference was found in age among groups $(\mathrm{P}=0.027)$.

Mean BMI was 26.4 (18.7-31.8) in patients with BPH, 24.4 (18.5-33) in patients with prostate cancer, and 28.01 (21.2-39.1) in the control group. A significant difference was observed in BMI among groups $(\mathrm{P}=0.001)$.

Significant differences were observed in total PSA, free PSA, free/total PSA ratio, and prostate weight measured by TRUS among groups $(\mathrm{P}<0.001 ; \mathrm{P}=0.02 ; \mathrm{P}<0.001$; and $\mathrm{P}<$ 0.001 , respectively). The results are summarized in Table 1 .

Table 1. Serum concentrations and demographic charecteristics of men in study groups.

\begin{tabular}{lcccc}
\hline & BPH & Prostate cancer & Control group \\
\cline { 2 - 4 } & Mean (min-max) & Mean (min-max) & Mean $(\min -\max )$ \\
\hline Age & $65.5(52-78)$ & $68.2(51-83)$ & $62.8(52-78)$ & 0.027 \\
BMI & $26.4(18.7-31.8)$ & $24.4(18.5-33)$ & $28.01(21.2-39.1)$ & 0.001 \\
Total PSA & $7.8(0.4-40.7)$ & $150.3(5.1-1042)$ & $1.4(0.5-2.5)$ & $<0.001$ \\
Free PSA & $1.53(0.1-9.21)$ & $34.37(0.5-477)$ & $0.65(0.2-1.33)$ & 0.020 \\
Prostate volume & $67.04(26-133)$ & $57.05(12-165)$ & $32.1(20-58)$ & $<0.001$ \\
Free/total PSA & $0.26(0.03-0.9)$ & $0.18(0.3-0.6)$ & $0.45(0.29-0.62)$ & $<0.001$ \\
\hline
\end{tabular}

A significant difference was observed in the $\mathrm{Q}$ max value measured by uroflowmetry among groups $(\mathrm{P}<0.001)$. There was also a significant difference in the amount of urine voided among groups $(\mathrm{P}<0.001)$. A significant difference was found in post-voidal amount of residual urine among groups $(\mathrm{P}<0.001)$.

Mean IPSS score was 23.6 (14-29) in patients with BPH, 20.2 (10-28) in patients with prostate cancer, and $3.9(0-10)$ in controls. Significant differences were found in the IPSS score among groups $(\mathrm{P}=0.001)$. There were also significant differences in erectile dysfunction score among groups $(\mathrm{P}=0.004)$. The results are summarized in Table 2. 
Table 2. Clinical parameters of men in study groups.

\begin{tabular}{lccrr}
\hline & BPH & Prostate cancer & Control group \\
\cline { 2 - 4 } & Mean (min-max) & Mean (min-max) & Mean $(\min -$ max $)$ \\
\hline Q max & $8.8(3-18)$ & $9.7(2-28)$ & $21.3(15-29)$ \\
PVR & $122.4(0-700)$ & $79.2(0-325)$ & $1.3(0-20)$ & $<0.001$ \\
IPSS & $23.6(14-29)$ & $20.2(10-28)$ & $3.9(0-10)$ & $<0.001$ \\
EDFS & $36.2(6-68)$ & $25.9(5-68)$ & $43.6(7-72)$ & $<0.001$ \\
\hline
\end{tabular}

Four gene regions involved in androgen synthesis were evaluated for polymorphisms. In the prostate cancer group, a significant difference was observed in only a homozygote variant located on the PSA-158 (G/A) gene. The results are summarized in Table 3.

Age, total PSA, free PSA, free/total PSA ratio, prostate weight, and Q max were reanalyzed. Prostate weight was classified as $\leq 30 \mathrm{~g}$ and $>30 \mathrm{~g}$, while Q max value as $\leq 14$ and $>14 \mathrm{~mL} / \mathrm{s}$, which were used in the analyses after transformation into nominal values. Of these parameters, only Q max values expressed statistical significance for the homozygote variant $(\mathrm{P}<0.05)$. The likelihood of the PSA-158 (G/A) polymorphism being homozygote found to be 5.8-fold higher in prostate cancer patients with Q $\max >14 \mathrm{~mL} / \mathrm{s}$ then in patients with $\mathrm{BPH}$ and control group, as shown in Figure 2.

Table 3. Single-nucleotide polymorphisms of men in study groups.

\begin{tabular}{|c|c|c|c|c|c|}
\hline & & \multicolumn{3}{|c|}{ Group } & \multirow[t]{2}{*}{ Total } \\
\hline & & $\mathrm{BPH}(\mathrm{N}=28)$ & Prostate cancer $(\mathrm{N}=32)$ & Control $(\mathrm{N}=30)$ & \\
\hline \multirow[t]{3}{*}{$P S A-158(\mathrm{G} / \mathrm{A})$} & Normal & 8 & 11 & 7 & 26 \\
\hline & Heterozygote & 13 & 21 & 13 & 47 \\
\hline & Homozygote & 7 & 0 & 10 & 17 \\
\hline \multirow[t]{3}{*}{ CYP17 Geni $-34 \mathrm{~T} / \mathrm{C}$} & Normal & 9 & 16 & 16 & 41 \\
\hline & Heterozygote & 14 & 10 & 12 & 36 \\
\hline & Homozygote & 5 & 6 & 2 & 13 \\
\hline \multirow[t]{3}{*}{$S R D 5 A 2$ geni V89L } & Normal & 16 & 19 & 13 & 48 \\
\hline & Heterozygote & 11 & 9 & 15 & 35 \\
\hline & Homozygote & 1 & 4 & 2 & 7 \\
\hline \multirow[t]{3}{*}{ CYP19 $1531 \mathrm{C}>\mathrm{T}$} & Normal & 6 & 8 & 13 & 25 \\
\hline & Heterozygote & 17 & 17 & 10 & 44 \\
\hline & Homozygote & 5 & 7 & 7 & 19 \\
\hline
\end{tabular}

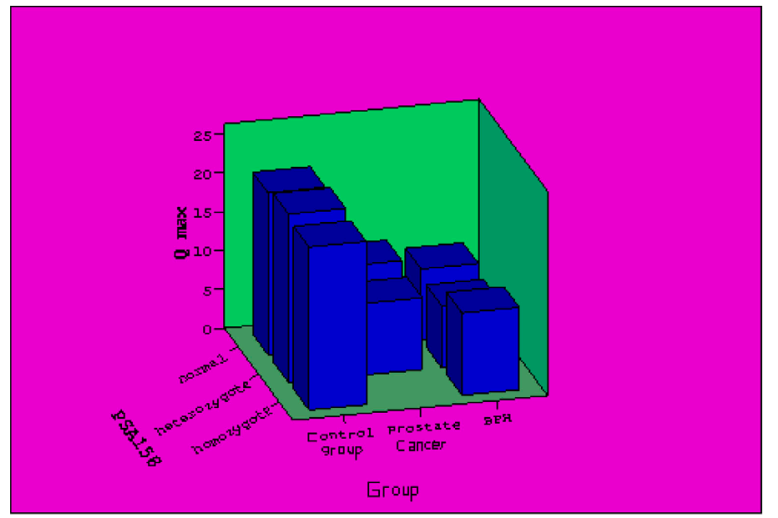

Figure 2. Mean Q max value of $P S A-158$ (G/A) polymorphism among study groups. 


\section{DISCUSSION}

Although incidence of prostate cancer and BPH increases with age, the etiopathogenesis is not fully understood. It is known that estrogens in combination with androgens as well as steroid metabolism disorders are the main risk factors of BPH pathogenesis (Geller et al., 1976; Rohrmann et al., 2007). It has been suggested that inefficiencies in the apoptotic process and impaired interaction between the stroma-epithelium contributes to abnormal prostate proliferation (Konvar et al., 2008).

Genetic sequencing studies have revealed several regions harboring different genes in various diseases; however, these studies alone failed to limit the number of candidate genes. Thus, most studies use 2 or more genetic techniques rather than 1 gene set in BPH (Konvar et al., 2008). The key role of androgens in prostate growth and prostate cancer development may be related to variability in genes from androgen biosynthesis (Konvar et al., 2008).

Although current evidence indicates that prostate cancer results from several factors, including ethnic, environmental, genetic, hormonal, and dietary factors, its etiology remains unknown. As the incidence of prostate cancer continues increasing, it becomes more important to identify molecular markers that may serve as indicators for disease risk and can be used to develop early detection methods. For prostate cancer, a number of candidate genes have been reported, including those affecting cellular growth and differentiation (Tayeb et al., 2003).

The main goal of this study is to identify molecular markers that are essential in the development of BPH and prostate cancer. In our study, the effects of gene regions including CYP19 $1531 \mathrm{C}>\mathrm{T}, S R D 5 A 2 \mathrm{~V} 89 \mathrm{~L}, C Y P 17-34 \mathrm{~T} / \mathrm{C}$, and PSA-158 (G/A) on BPH and prostate cancer were evaluated.

A significant difference was found in the $\mathrm{BPH}$ and prostate cancer groups compared to the control group regarding BMI, total PSA, free PSA, prostate weight, Q max, IPSS, and erectile dysfunction score. This finding may be attributed to the lack of difficulty in voiding as a complaint and/or greater mean age.

In a population-based, case-control study in China, Kurosaki et al. (2009) evaluated prostate cancer and BPH risk in relation to changes in CYP17. The study included 174 cases with prostate cancer, 182 cases with BPH, and 274 healthy controls. The authors failed to identify a significant relationship between $C Y P 17$ and prostate cancer risk or BPH. In gene polymorphism studies for CYP17, no significant difference was found in BPH risk by Roberts et al. (2006), and no significant difference was observed in the population with prostate cancer by Tigli et al. (2003). In agreement with previous studies, no significant difference was observed for the CYP17 gene polymorphism $(-34 \mathrm{~T} / \mathrm{C})$ in our study $(\mathrm{P}=0.303)$.

In a meta-analysis by Wang et al. (2010), a significant relationship was observed between the SRD5A2 V89L gene and prostate cancer risk in a European population below 65 years of age. In the same study, no significant relationship was observed when all races were included. These results may have been caused by ethnic differences between Europeans and Asians or Africans. Studies by Shibata et al. (2001) and Li et al. (2003), failed to find a significant relationship between BPH and the $S R D 5 A 2$ V89L gene. In another retrospective study, positive associations for several SRD5A1 and SRD5A2 variations as independent predictors of biochemical relapse after radical prostatectomy were identified (Audet-Walsh et al., 2011). In addition, $S R D 5 A$ markers differentially affected sex-steroid profiles of dihydrotestosterone and its metabolites in both the circulation and prostatic tissues of patients with prostate cancer (Lévesque et al., 2014). In our study, no significant difference was found in the SRD5A2 V89L 
gene among the $\mathrm{BPH}$, prostate cancer, and control groups $(\mathrm{P}=0.359)$. This finding may have been affected by the ethnicity of our population, which had migrated from Asia.

Roberts et al. (2006) found no significant difference in BPH for the CYP19 $1531 \mathrm{C}>\mathrm{T}$ gene polymorphism, whereas the homozygote variant of the CYP19 $1531 \mathrm{C}>\mathrm{T}$ gene polymorphism was significantly higher in cases with a prostate weight $>30 \mathrm{~g}(\mathrm{P}=0.006)$. Suzuki et al. (2003) reviewed 101 patients who had a first-degree relative with prostate cancer. The authors analyzed estrogen receptor- $\alpha, C Y P 19$, and catechol- $O$-methyl transferase genes. They found that genotypes considered as being high risk (in T/T'; $\mathrm{C} / \mathrm{T}$ in $C Y P 19$, and $\mathrm{G} / \mathrm{A}$ in $\mathrm{T} / \mathrm{T}^{\prime}$ and catechol- $O$-methyl transferase) increased prostate cancer risk. In our study, no significant difference was observed in the CYP19 $1531 \mathrm{C}>\mathrm{T}$ gene region among $\mathrm{BPH}$, prostate cancer, and control groups in our region $(\mathrm{P}=0.253)$. This lack of statistical significance may be related to the absence of consanguinity among our patients with prostate cancer. In contrast to the study by Roberts et al. (2006), no significant difference was found in our cases with a prostate weight $>30 \mathrm{~g}(\mathrm{P}=0.748)$.

Roberts et al. (2006) reported that the presence of 2 or more high-risk genotype (HSD3B1: c.1100A/C and c. 1012C/T, CYP19: c. 1531C/T and repeat of TTTA more than 175; PSA gene: $158 \mathrm{G} / \mathrm{A}, 252 \mathrm{G} / \mathrm{A}$ and 205 ins a) in the PSA gene may increase the risk of BPH development. In a study by Dos Santos et al. (2008), prostate cancer risk was found to be higher in patients with the normal GG genotype variant compared to those with the AG heterozygote genotype and AA homozygote genotype $(\mathrm{P}=0.00138)$. They found considerably lower PSA values in the AA genotype when compared to the GG allele; however, the difference was not significant $(6.44 \pm 1.64$ vs $10.44 \pm 10.06 \mathrm{ng} / \mathrm{mL} ; \mathrm{P}=0.0482)$. In a study of a Turkish population, Günes et al. (2007) found that the frequency of GA and GG genotypes in PSA 158 gene was significantly higher in patients with prostate cancer compared to controls $(\mathrm{P}=0.017$ and $\mathrm{P}=0.019$, respectively). A significant relationship was observed between the GG genotype and $\mathrm{BPH}(\mathrm{P}=0.033)$. In the studies by Salinas et al. (2005) and Jesser et al. (2008), no significant difference was found in the PSA-158 G/A polymorphism for prostate cancer. However, in a meta-analysis including 12 trials, the $P S A-158 \mathrm{G} / \mathrm{A}$ polymorphism had no effect on prostate cancer risk.

In our study, the $P S A-158 \mathrm{G} / \mathrm{A}$ polymorphism was found to be statistically significant among $\mathrm{BPH}$, prostate cancer, and control groups $(\mathrm{P}=0.015)$. Chi-square tests showed significant associations in prostate cancer, but not in BPH. No homozygote variant was observed in the $P S A-158 \mathrm{G} / \mathrm{A}$ gene for prostate cancer. No subgroup analysis was performed because of the lack of the AA allele. After combining groups, the homozygote variant was evaluated for its relationship to age, BMI, total PSA, free PSA, free/total PSA ratio, prostate weight $\leq 30$ or $>30 \mathrm{~g}$, and $\mathrm{Q} \max \leq 14 \mathrm{or}>14 \mathrm{~mL} / \mathrm{s}$. No statistically significant relationship was found in these factors, except in the subgroup regression analysis of $\mathrm{Q} \max \leq 14$ or $>14 \mathrm{~mL} / \mathrm{s}(\mathrm{P}=0.015)$. Subgroup analysis showed that the likelihood of being homozygote for prostate cancer was 5.8 -fold higher in cases with Q $\max >14 \mathrm{~mL} / \mathrm{s}$.

\section{CONCLUSIONS}

We hypothesized that the homozygote variant of the PSA-158 G/A gene plays a protective role against prostate cancer, similarly to the study by Günes et al. (2007). However, we found no relationship with BPH. The main limitation of our study was the low number of subjects included, and thus our results are preliminary. Studies on polymorphisms should include high numbers of both study and control subjects. 


\section{REFERENCES}

Audet-Walsh E, Bellemare J, Nadeau G, Lacombe L, et al. (2011). SRD5A polymorphisms and biochemical failure after radical prostatectomy. Eur. Urol. 60: 1226-1234.

Chakraborty A, Murthy NS, Chintamani C, Bhatnagar D, et al. (2007). CYP17 gene polymorphism and its association with high-risk north Indian breast cancer patients. J. Hum. Genet. 52: 159-165.

Chapple CR (1999). BPH disease management. Eur. Urol. 36: 1-6.

Cunha CR, Chung LWK, Shannon JM, Taquchi O, et al. (1983). Hormone-induced morphogenesis and growth: role of mesenchymal-epithelial interactions. Recent Prog. Hormone Res. 39: 559-598.

Donovan JL, Kay HE, Peters TJ, Abrams P, et al. (1997). Using the ICSOoL to measure the impact of lower urinary tract symptoms on quality of life: evidence from the ICS-'BPH' study. International Continence Society-Benign Prostatic hyperplasia. Br. J. Urol. 80: 712-721.

Dos Santos RM, de Jesus CM, Trindade Filho JC, Trindade JC, et al. (2008). PSA and androgen-related gene (AR, CYP17, and CYP19) polymorphisms and the risk of adenocarcinoma at prostate biopsy. DNA Cell. Biol. 27: 497-503.

Geller J, Albert J, Lopez D, Geller S, et al. (1976). Comparison of androgen in benign prostatic hypertrophy (BPH) and normal prostate. J. Clin. Endocrinol. Metab. 43: 686-688.

Günes S, Bagci H, Sarikaya S, Bilen CY, et al. (2007). Prostate-specific antigen and 17-hydroxylase polymorphic genotypes in patients with prostate cancer and benign prostatic hyperplasia. DNA Cell. Biol. 26: 873-878.

Hur SE, Lee S, Lee JY, Moon HS, et al. (2007). Polymorphisms and haplotypes of the gene encoding the estrogen metabolizing CYP19 gene in Korean women: no association with advanced stage endometriosis. J. Hum. Genet. 92: 703-711.

Jesser C, Mucci L, Farmer D, Moon C, et al. (2008). Effects of G/A polymorphism, rs266882, in the androgen response element 1 of the PSA gene on prostate cancer risk, survival and circulating PSA levels. Br. J. Cancer 99: 1743-1747.

Kakinuma H, Tsuchiya N, Habuchi T, Ohyama C, et al. (2004). Serum sex steroid hormone levels and polymorphisms of CYP17 and SRD5A2: implication for prostate cancer risk. Prostate Cancer and Prostatic Diseases 7: 333-337.

Konvar R, Chattopadhyay N and Bid HK (2008). Genetic polymorphism and pathogenesis of benign prostatic hyperplasia. BJU Int. 102: 536-544.

Kurosaki T, Suzuki M, Enomoto Y, Arai T, et al. (2009). Polymorphism of cytochrome P450 2B6 and prostate cancer risk: A significant association in a Japanese population. Int. J. Urol. 16: 364-368.

Lévesque É, Laverdière I, Lacombe L, Caron P, et al. (2014). Importance of $5 \alpha$-reductase gene polymorphisms on circulating and intraprostatic androgens in prostate cancer. Clin. Cancer Res. 20: 576-584.

Li Z, Habuchi T, Mitsumori K, Kamoto T, et al. (2003). Association of V89L SRD5A2 polymorphism with prostate cancer development in a Japanese population. J. Urol. 169: 2378-2381

Lustig B and Behrens J (2003). The Wnt signaling pathway and its role in tumor development. J. Cancer Res. Clin. Oncol. 129: 199-221.

Parkin DM, Bray FI and Devesa SS (2001). Cancer burden in the year 2000: the global picture. Eur. J. Cancer 37: S4-66.

Parkin DM, Bray F, Ferlay J and Pisani P (2005). Global cancer statistics. CA Cancer J. Clin. 55: 74-108.

Roberts RO, Bergstralh EJ, Farmer SA, Jacobson DJ, et al. (2006). Polymorphisms in genes involved in sex hormone metabolism may increase risk of benign prostatic hyperplasia. Prostate 66: 392-404.

Rohrmann S, Nelson WG, Rifai N, Kanarek N, et al. (2007). Serum sex steroid hormones and lower urinary tract symptoms in third national health and nutrition examination survey (NHANES III). Urology 69: 708-703.

Salinas CA, Austin MA, Ostrander EO and Stanford JL (2005). Polymorphisms in the androgen receptor and the prostatespecific antigen genes and prostate cancer risk. Prostate 65: 58-65.

Shibata A, Stamey TA, McNeal JE, Cheng I, et al. (2001). Genetic polymorphisms in the androgen receptor and type II 5-reductase genes in prostate enlargement. J. Urol. 166: 1560-1564.

Silig Y, Pınarbasi H, Günes S, Ayan S, et al. (2006). Polymorphisms of CYP1A1, GSTM1, GSTT1, and prostate cancer risk in Turkish population. Cancer Invest. 24: 41-45.

Suzuki K, Nakazato H, Matsui H, Koike H, et al. (2003). Genetic polymorphisms of estrogen reseptor alpha, CYP19, catecholO-methyltransferase are associated with familial prostate carcinoma risk in a Japanese population. Cancer 98: 1411-1416.

Tayeb MT, Clark C, Haites NE, Sharp L, et al. (2003). CYP3A4 and VDR gene polymorphisms and the risk of prostate cancer in men with benign prostate hyperplasia. Br. J. Cancer 88: 928-932.

Tigli H, Yazici H and Dalay N (2003). Cyp17 genetic polymorphism in prostate cancer and benign prostatic hyperplasia. Res. Commun. Mol. Pathol. Pharmacol. 113: 307-314.

Wang C, Tao W, Chen Q, Hu H, et al. (2010). SRD5A2 V89L polymorphism and prostate cancer risk: a meta-analysis. Prostate 70: 170-178

Whingo PA, Tong T and Bolden S (1995). Cancer statistics 1995. CA Cancer J. Clin. 45: 8-30.

Xue W, Irvine RA, Yu MC, Ross RK, et al. (2000). Susceptibility to prostate cancer: interaction between genotypes at the androgen receptor and prostate-specific antigen loci. Cancer Res. 60: 839-841. 